\title{
Surgical denervation significantly reduces articular synovitis in patients with osteoarthritis of the first carpometacarpal joint
}

\author{
Joan Arenas Prat ${ }^{1 *}$, Daniel Cercós Casale ${ }^{2}$ \\ ${ }^{1}$ Orthopaedics Department, Serveis Mèdics Penedès,Barcelona, Spain. ${ }^{2}$ Radiology Department, Serveis Mèdics Penedès, \\ Barcelona, Spain.
}

This study aimed to test the hypothesis that surgical joint denervation produces a significant reduction of synovitis.

A retrospective study of sonographic Doppler images was used to assess synovitic changes in 16 first carpometacarpal joints of 15 patients (mean age $63.31+/-8.20$ ) who had undergone surgical denervation to treat osteoarthritic pain. The paired t-test was used to compare Doppler sonographic signal differences between the two time points of pre-operative and at least six months after the operation in order to evaluate variations in articular synovitis. To measure the severity of synovitis, a semi-quantitative scoring system was used in which the intensity of the synovial blood flow was graded in a four-step scale; 0 meant no flow in the synovium, 1 corresponded to single vessel signals, 2 meant confluent vessel signals in less than half of the area of the synovium, and 3 showed vessel signals in more than half of the area of the synovium.

A significant difference $(P$ value $<0.0054)$ was found between the pre-operative and post-operative mean values of joint synovitis $(1.44+/-0.814$ vs $0.62+/-0.619)$ with a $95 \%$ confidence interval.

This study proposes that denervation of the first carpometacarpal joint, apart from being an effective treatment to improve arthritic pain, significantly reduces joint synovitis, which may eventually slow down or even interrupt the progression of osteoarthritis.

Keywords: Arthritis; First carpometacarpal joint; Denervation; Synovitis

\section{Introduction}

When conservative measures have failed, surgical joint denervation is a well-established procedure for relieving joint pain by interrupting neural pathways that transmit the pain message from the joint to the brain. This method was first proposed by Camitz in 1933 at the hip-joint level by means of a neurotomy of the obturator nerve [1]. In 1966, Wilhelm described a technique for wrist denervation [2], and since then, several procedures based upon the same principles have been described at virtually any hand joint [3-7].

First carpometacarpal joint denervation is a relatively simple technique that does not preclude further surgery, such as arthrodesis, trapeziectomy, or joint replacement, if the results are not satisfactory. Moreover, it does not interfere with joint biomechanics or proprioception [8], and its recovery time is much quicker than traditional techniques. Relative contraindications are joint instability and gross deformity. Relevant complications such as Charcot's joint have not been reported yet in the medical literature. For these reasons, in our institution it has become the first sur- gical option for treating painful osteoarthritis in view of its satisfactory results.

Initially its main goal was pain relief. However, to our surprise, patients also noticed that other inflammatory signs such as swelling, erythema, or increased local temperature had subsided or partially improved after treatment. Synovitis is a common finding in osteoarthritic joints and is the main cause of pain in these patients. However, it is not constant and may fluctuate in different situations such as excessive physical activity. The absence of pain in patients with a diagnosis of osteoarthritis may be explained by the low degree of synovitis. Likewise, exacerbations of synovitis will cause deterioration of pain.

To further confirm these incidental findings, we retrospectively reviewed and analyzed the possible sonographic changes in inflammation and synovitis in sixteen first carpometacarpal joints of fifteen patients who had undergone first carpometacarpal joint denervation at our institution over a two-year period. The results are discussed in the present article together with the principles of neurogenic inflammation as a possible explanation for the beneficial effects of 
surgical joint denervation on synovitis and inflammation.

\section{Joint Innervation}

Apart from sympathetic and parasympathetic fibers, innervation of the joints is supplied by primary and accessory sensory branches that can be both afferent and efferent. Primary branches arise from peripheral nerves passing near the joint, and accessory branches are given off by intramuscular nerves crossing the joint capsule or attached to it. Some joints, especially at hand level, also receive a nerve supply from cutaneous nerves in the overlying skin. There is evidence of innervation of all articular structures such as capsule, synovium, ligaments, tendons, bone marrow and periosteum [9].

There are two types of nerve fibers, myelinated $(>1 \mu \mathrm{m})$ and unmyelinated $(<1 \mu \mathrm{m})$. Proprioceptive and nociceptive functions are carried out by myelinated articular A and B fibers which supply ligaments and capsule. Capsule is also supplied by unmyelinated $\mathrm{C}$ fibers that have nociceptive functions. Moreover, synovium is innervated by myelinated and unmyelinated fibers that have sympathetic-adrenergic functions and are located around the larger blood vessels to control the articular blood flow. Unmyelinated $\mathrm{C}$ fibers arise from cell bodies located in the dorsal root ganglion and are responsible for pain transmission. They are not normally active, as they only fire during tissue damage, either mechanical or chemical, noxious heat or inflammation through mediators such as bradykinins, prostaglandins, or protons that activate receptors located in the joint nerve endings. Apart from a peripheral projection, these cell bodies have a central projection to the spinal cord, from which they synapse with ascending fibers. In response to nerve endings activation, cell bodies manufacture neuropeptides which are transported both centrally and peripherally along the nerve axons and released into the joint from the synovial membrane. It is widely accepted that transient receptor potential receptor vanilloid-1 (TRPV1) and transient potential receptor ankyrin-1 (TRPA1) expressing primary afferents are the fibers upon which neurogenic arthritis is dependent [9]. Hence, afferent fibers can behave as efferent as well. The most relevant neuropeptides are substance $\mathrm{P}$ and calcitonin gen-related peptide (CGRP). Both, as mentioned previously, are released into the joint by nerve terminals and can cause vasodilatation and edema and can stimulate mast cells with the release of histamine and other inflammatory mediators [10]. In the medical literature, numerous studies were found which confirmed that free nerve endings containing substance P modulate, or even initiate, inflammation and the pain pathway in osteoarthritis [11-24]. In addition, recent studies have demonstrated that Interleukin-6, which is increased in the synovial fluid of patients with symptomatic osteoarthritis, causes enhanced release of neuropeptides from sensory neurons. Therefore, Inteleukin-6 is not only involved in pain generation in osteoarthritis, but also in the coordination and maintenance of the inflammatory reaction via the nervous system $[25,26]$.

\section{Materials and Methods \\ Patients}

In our institution, all patients suffering from osteoarthritis of the first carpometacarpal joint, in addition to radiological examination, undergo routine sonographic imaging to assess the degree of synovitis and the likely progression of their condition. Patients have plain antero-posterior and lateral XR views and also a sonographic Doppler scan of the same joint following the first visit and another Doppler scan when they are finally discharged after treatment six months later.

For the present study the pre- and post-operative ultrasound Doppler images of 13 female and 2 male patients (one male had both hands operated) who had undergone denervation of the first carpometacarpal joint during a two-year period were retrospectively evaluated and compared. Exclusion criteria were have received intra-articular steroid injections during a six-month period before sonographic examination in order to avoid interference with the degree of joint synovitis.

Diagnoses of osteoarthritis were confirmed using the American College of Rheumatology criteria of 1990 [27], and post-operative sonographic examination was carried out in all cases at least six months after the operation when surgical inflammation had subsided.

The mean age of participants was 63.3 years, ranging from $48-76$ years with a standard deviation of 8.2 years, and the male:female ratio was 2:13.

\section{Methods \\ Surgical technique}

The same surgical technique through a Wagner approach [4] was used in all patients and performed by the same surgeon. This procedure involves the neurotomy of sensory articular branches of the first carpometacarpal joint. These branches arise from the superficial branch of the radial nerve, lateral antebrachial cutaneous nerve, palmar branch of median nerve, sensory rami from thenar branch and sensory branch from the deep branch of the ulnar nerve. Patients were routinely assessed two weeks after the operation to have the sutures removed and start early and gradual mobilization. There were no significant complications, and at least six months later, when most post-operative inflammation and scar tissue had subsided and just before discharge, another Doppler sonographic examination had been carried just before discharge.

\section{Image data acquisition}

According to several authors, ultrasound examination of joints offers an easy and reliable way to measure soft tissue inflammation and progression of osteoarthritis [28, 29]. 
To analyze those parameters, a semi-quantitative scoring system in which the intensity of the synovial blood flow of synovitis is graded in a four-step scale is routinely used in our institution [28]. The power Doppler signal is used to display the flow signal in the synovium $(0=$ no flow in the synovium, 1 = single vessels signals, $2=$ confluent vessel signals in less than half of the area of the synovium, $3=$ vessel signals in more than half of the area of the synovium). Only the strongest pre- and post-operative Doppler signals are scored.

For the present study, the medical records of patients in the hospital database who had undergone denervation of the first carpo-metacarpal joint during a two-year period were reviewed. Doppler ultrasound examination in our institution was carried out from volar to radio-volar aspect of the first carpometacarpal joint by one of the authors, a senior Consultant Radiologist, using a Toshiba Xario 200 ultrasound equipment (Toshiba Medical Systems Corporation, Otawara, Japan) with a $10 \mathrm{MHz}$ linear transducer and the same machine Doppler settings for all patients.

Ultrasound joint examination was performed by applying light pressure and a large quantity of visible scanning gel between the transducer and the skin. Patients were sitting in a relaxed and comfortable position with their hands supported on a soft table. To avoid circadian variations of the inflammation, sonographic examinations were performed in the morning. Patients were routinely advised to stop taking oral anti-inflammatory medication before sonographic examination so as to prevent masking articular inflammatory changes. All sonographies were graded to evaluate Doppler signal and the degree of inflammation before the operation and at discharge, usually six months postoperatively.

The paired t-test was used to compare Doppler sonographic signals between the pre-operative stage and at least six months after the operation in order to evaluate variations in articular synovitis.

\section{Results}

Of the study group comprising all 15 patients meeting the study criteria, the mean age at time of the operation was $63.3+/-8.2$ years. The male: female ratio was $2: 13$; one male patient underwent bilateral surgery. All patients were followed up for a minimum period of six months after their operations, and before discharge, a final Doppler scan of the first carpometacarpal joint was done. Synovitis was measured using a semi quantitative scale ranging from 0 to 3. Other functional outcomes such as pain relief or grip strength were not accurately recorded in patients' medical notes. Nonetheless, for the purpose of the present study, the focus was placed mainly on inflammatory changes rather than symptoms. These results have been included in Table 1.

Table 1. Demographic data of patients including gender and dominant hand

\begin{tabular}{|c|c|c|c|c|c|}
\hline Pacient & Gender & Side & Age & Pre-operative & Post-operative \\
\hline 1 & $\mathrm{~F}$ & $\mathrm{~L}$ & 51 & 2 & 1 \\
\hline 2 & M & $\mathrm{L}$ & 70 & 1 & 1 \\
\hline 3 & $\mathrm{~F}$ & $\mathrm{~L}$ & 48 & 2 & 0 \\
\hline 4 & $\mathrm{~F}$ & $\mathrm{~L}$ & 60 & 1 & 1 \\
\hline 5 & $\mathrm{~F}$ & $\mathrm{~L}$ & 61 & 1 & 1 \\
\hline 6 & $\mathrm{~F}$ & $\mathrm{R}$ & 69 & 0 & 1 \\
\hline 7 & $\mathrm{~F}$ & $\mathrm{R}$ & 59 & 1 & 0 \\
\hline 8 & $\mathrm{~F}$ & $\mathrm{R}$ & 60 & 1 & 1 \\
\hline 9 & $\mathrm{~F}$ & $\mathrm{~L}$ & 71 & 0 & 0 \\
\hline 10 & $\mathrm{~F}$ & $\mathrm{~L}$ & 58 & 3 & 0 \\
\hline 11 & $\mathrm{~F}$ & $\mathrm{R}$ & 74 & 2 & 1 \\
\hline 12.left & M & $\mathrm{L}$ & 60 & 2 & 0 \\
\hline 12.right & M & $\mathrm{R}$ & 60 & 2 & 2 \\
\hline 13 & $\mathrm{~F}$ & $\mathrm{R}$ & 76 & 2 & 0 \\
\hline 14 & $\mathrm{~F}$ & $\mathrm{~L}$ & 62 & 1 & 0 \\
\hline 15 & $\mathrm{~F}$ & $\mathrm{~L}$ & 74 & 2 & 1 \\
\hline
\end{tabular}

F: female; M: male; L: lefthanded and R: righthanded. The semi-quantitative pre and post-operative values of joint synovitis range from 0 (no synovitis), 1 (sparse non confluent Doppler signals) 2 (confluent Doppelr signals affecting les than 50\% of the scanned joint area) to 3 (confluent Doppler signals affecting more than $50 \%$ of the scanned joint area). 
Doppler signal values before and after denervation of all sixteen joints were given a value which ranged from 0 (no Doppler signal) to 3 (confluent vessel Doppler signals in more than half of the area of the synovium). Descriptive statistical indices of the Doppler signal of articular inflammation are shown in Table 2.

Table 2. Descriptive statistical indexes of Doppler signal of articular inflammation

\begin{tabular}{ccc}
\hline Statistical index & $\begin{array}{c}\text { Pre-operative Synovitis } \\
(\mathbf{n}=\mathbf{1 6})\end{array}$ & $\begin{array}{c}\text { Post-operative synovitis } \\
(\mathbf{n}=\mathbf{1 6})\end{array}$ \\
\hline Mean & 1,44 & 0,62 \\
Median & 1,5 & 1 \\
Standard deviation & 0,814 & 0,619 \\
Pearson asymmetry & $-0,195$ & 0,421 \\
Kurtosis & $-0,208$ & $-0,454$ \\
\hline
\end{tabular}

Where 0 means no synovitis, 1 corresponds to sparse non confluent Doppler signals, 2 confluent Doppler signals affecting less than $50 \%$ of the scanned joint area and 3 confluent Doppler signals affecting more than $50 \%$ of the scanned joint area and 3 for severe synovitis of the joint.

Pre- and post-operative measurements had significant $P$ values of 0.97480 and 0.99616 , respectively, and the decision criteria for both groups fulfilled the requirements of normal data distribution. The statistical analysis of the sonographic Doppler images of the 16 joints that underwent surgical denervation showed a significant decrease in synovitis from a mean of $1.44+/-0.814$ to $0.62+/-0.619$ $(P$ value $<0.0054)$.

\section{Discussion}

\section{Joint denervation and its influence on neurogenic in-} flammation

Surgical denervation is a relatively simple technique used to treat osteoarthritic pain. It aims to divide articular sensory branches from a specific joint in order to interrupt pain transmission. It does not significantly modify articular structures, and for this reason further surgery is not precluded if results are not satisfactory. Furthermore, it does not affect joint biomechanics or proprioception. Currently, it is mainly carried out in hand joints, although some authors have described denervation techniques in other sites such as ankle, knee, elbow, and shoulder [30, 31]. Synovectomy, likewise, is another mechanism of local depletion of sensory nerve terminals that may abolish the release of neuropeptides. This could explain the positive effects of the procedure [32]. Based on the same principles and in view of its satisfactory results, lumbar facet joint radio-frequency denervation has become a common option for treating painful degenerative arthritis at spinal facet joint level by means of selectively destroying articular nerve fibers by heat produced by radio waves and delivered by an electrode.

Joint denervation, apart from interrupting pain transmission, theoretically may also affect the intra-articular release of neuropeptides from sensory nerve terminals. These nerve endings participate in joint inflammation through synovitis, which has been reported to cause chronic joint destruction, leading to degenerative or inflammatory arthritis [33-35]. Furthermore, in the medical literature, several striking examples of interaction between the nervous system and the inflammatory process have been reported: patients who suffered a stroke, polio, or syphilis and, later on life, developed systemic inflammatory conditions such as rheumatoid or psoriatic arthritis or had an atypical disease presentation. Instead of the inflammatory symmetry typical of these conditions, only neurologically intact limbs developed joint inflammation, demonstrating that denervated joints were spared [36-39]. The initial explanation for these cases was the lack of mobilization of the affected limb joints, which would prevent mechanical wear and tear of the articular surfaces. However, recent reports suggest otherwise $[40,41]$. In these striking cases, the spared joints of fingers with an old lesion to the digital nerves had been mobilized normally, and they were never affected by the inflammatory process. Stangenberg et al. successfully modelled hemiplegia-induced protection from arthritis in some mouse strains [42].

The present study confirms a significant reduction in joint synovitis following surgical denervation. This could be explained by the intra-articular depletion of inflammatory neuropeptides following the neurectomy of articular sensory branches. Hence, from these premises, it was hypothesized that selective division of articular nerves could possibly slow down or even interrupt further articular damage in early osteoarthritic joints, when synovitis or inflammation, rather than distorted joint biomechanics, prevail.

The limitation of the present study is its reduced number of patients and we believe that further prospective studies with bigger series are needed during longer periods of time to confirm this hypotheses. 
We think that this model also applies to other joints as neurogenic inflammation is a well-recognized pathophysiological process that can affect any synovial articulation.

\section{Conclusion}

Surgical denervation of the first carpometacarpal joint, apart from improving osteoarthritic pain by interrupting the neurological pathways that transmit the signal to the brain, significantly reduces articular inflammation and synovitis. In the present study the levels of intra-articular neuropeptides released by nerve endings, mainly substance $\mathrm{P}$ and CRGP have not been evaluated but the depletion of these neuropeptides could explain the inflammatory changes.

Further prospective research with bigger series and longer follow up periods should be considered in order to investigate whether this reduction of inflammation can ultimately affect the progression of joint osteoarthritis.

\section{Acknowledgments}

The authors thank all those who helped them writing this paper.

\section{Conflict of Interest}

The authors declare no conflicts of interest. 


\section{References}

1. Camitz H. Die deformierende Hüftgelenksarthritis und speziell ihre behandlung. Acta Orthop Scand 1933; 4(3):193-213. doi.org/10.3109/17453673308988867.

2. Wilhelm A. Die Gelenkdenervation und ihre anatomischen Grundlagen. Vol. 86, 1 edn. Springer-Verlag Berlin Heidelberg; 1966.

3. Lórea PD. First carpometacarpal joint denervation: anatomy and surgical technique. Tech Hand Up Extrem Surg 2003; 7(1):26-31. doi: 10.1097/00130911-20030300000006.

4. Arenas-Prat J. Wagner approach for first carpometacarpal joint denervation. Tech Hand Up Extrem Surg 2012; 16(2):107-09. doi: 10.1097/BTH.0b013e31824f8c96.

5. Arenas-Prat J. Denervation of the distal interphalangeal joint. Tech Hand Up Extrem Surg 2012; 16(1):12-13. doi: 10.1097/BTH.0b013e3182296e68.

6. Lorea PD, Ezzedine R, Marchesi S. Denervation of the proximal interphalangeal joint: a realistic and simple procedure. Tech Hand Up Extrem Surg 2005; 8(4):262-65. doi: 10.1097/00130911-200412000-00010.

7. Arenas-Prat J. Denervation of the metacarpophalangeal joint. Tech Hand Up Extrem Surg 2014; 18(4):158-59. doi: 10.1097/BTH.0000000000000057.

8. Rein S, Winter J2, Kremer T, Siemers F, Range U, Euchner $\mathrm{N}$. Evaluation of proprioception in denervated and healthy wrist joints. J Hand Surg Eur Vol 2020; 45(4):408-13 doi: 10.1177/1753193419897192.

9. Donaldson L. Neurogenic Mechanisms in Arthritis. In: insights to neuroimmune biology. Edited by Berczi I, 2 edn. Elsevier, Amsterdam; 2009: 213-219.

10. Mapp PI. Innervation of the synovium. Ann Rheum Dis 1995; 54(5):398-03. doi: 10.1136/ard.54.5.398.

11. Goldring S, Goldring M. Structure and function of bone, joints and connective tissue. In: Pediatric Rheumatology: A Clinical Viewpoint. Edited by Sawhney S, Aggarwal A, 9 edn. Elsevier Saunders, Philadelphia; 2013: 11.

12. Wang H, Zhang X, He J, Zheng X, Li D, Li Z, et al. Increasing expression of substance $\mathrm{P}$ and calcitonin gen-related peptide in synovial tissue and fluid contribute to the progress of arthritis in developmental dysplasia of the hip. Arthritis Res Ther 2015; 17(1):4. doi: 10.1186/s13075014-0513-1.

13. Grässel SG. The role of peripheral nerve fibres and their neurotransmitters in cartilage and bone physiology and pathophysiology. Arthritis Res Ther 2014;16(6):485. doi: 10.1186/s13075-014-0485-1.

14. Zhang RX, Ren K, Dubner R. Osteoarthritis pain mechanism: Basic studies in animal models. Osteoarthritis Cartilage 2013; 21(9):1308-15. doi: 10.1016/j. joca.2013.06.013.

15. Mapp PI, McWilliams DF, TurleyMJ, Hargin E, Walsh DA. A role for the sensory neuropeptide calcitonin gen-related peptide in endothelial cell proliferation in vivo. $\boldsymbol{B r}$
J Pharmacol 2012; 166(4):1261-71. doi: 10.1111/j.14765381.2012.01848.x.

16. Wood J, Docherty R. Chemical activators of sensory neurons. Annu Rev Physiol 1997; 59:457-82. doi: 10.1146/ annurev.physiol.59.1.457.

17. Ogino S, Sasho T, Nakagawa K, Suzuki M, Yamaguchi S, Higashi M, et al. Detection of pain-related molecules in the subchondral bone of osteoarthritic knees. Clin Rheumatol 2009; 28(12):1395-02. doi: 10.1007/s10067-009-1258-0.

18. Saxler G, Löer F, Skumavc M, Pförtner J, Hanesch U. Localization of SP and CGRP-immunopositive nerve fibers in the hip joint of patients with painful osteoarthritis and of patients with painless failed total hip arthroplasties. Eur J Pain 2007; 11(1):67-74. doi: 10.1016/j. ejpain.2005.12.011. Epub 2006 Feb 7.

19. McDougall J. Arthritis and pain: Neurogenic origin of joint pain. Arthritis Res Ther 2006; 8(6):220. doi: 10.1186/ ar2069.

20. O'Connor TM, O'Connell J, O'Brien DI, Bredin CP, Shanahan F. The role of substance $\mathrm{P}$ in inflammatory disease. J Cell Physiol 2004; 201(2):167-80. doi: 10.1002/ jсp.20061.

21. Ordeberg G. Characterization of joint pain in human OA. Novartis Found Symp 2004; 260:105-15

22. Saito T. Neurogenic inflammation in osteoarthritis of the knee. Mod Rheumatol 2003; 13(4):301-04. doi: 10.3109/ s10165-003-0253-6.

23. Fortier LA. Nixon AJ. Distributional changes in substance P nociceptive fiber patterns in naturally osteoarthritic articulations. J Rheumatol 1997; 24(3):524-30.

24. Marshall KW, Chiu B, Inman RD. Substance P and arthritis: analysis of plasma and synovial fluid levels. Arthritis Rheum 1990; 33(1):87-90. doi: 10.1002/art.1780330111.

25. Tsuchida A I, Beekhuizen M, Bot A G J, Geurts B, Bekkers J E J, Dhert W J A, et al. The Role of IL-6 in Osteoarthritis and Cartilage Regeneration. Poster N0 1709. ORS 2012 Annual Meeting

26. Ebbinghaus M, Segond von Banchet G, Massier J, Gajda M, BrauerR, Kress M, et al. Interleukin-6-dependent influence of nociceptive sensory neurons on antigen-induced arthritis. Arthritis Res Ther 2015; 17:334. doi: 10.1186/ s13075-015-0858-0.

27. Altman R, Alarcon G, Appelrouth D, Bloch D, Borenstein $\mathrm{D}$, Brandt K, et al. The American College of Rheumatology criteria for the classification and reporting of osteoarthritis of the hand. Arthritis Rheum 1990; 33(11):160110. doi: 10.1002/art.1780331101.

28. Szkudlarek M, Court-Payen M, Jacobsen S, Klarlund M, Thomsen H, Østergaard M. Interobserver agreement in ultrasonography of the finger and toe joints in rheumatoid arthritis. Arthritis Rheum 2003; 48(4): 955-62. doi: 10.1002/art.10877.

29. Keen HI, Lavie F, Wakefield RJ, D’Agostino M-A, Berner 
Hammer H, Hensor E, et al. The development of a preliminary ultrasonographic scoring system for features of hand osteoarthritis. Ann Rheum Dis 2008; 67(5):651-55. doi: 10.1136/ard.2007.077081.

30. Dellon AL. Partial joint denervation I: wrist, shoulder and elbow. Plast Reconstr Surg 2009; 123(1):197-07. doi: 10.1097/PRS.0b013e31818cc23f.

31. Dellon AL. Partial joint denervation II: knee and ankle. Plast Reconstr Surg 2009; 123(1):208-17. doi: 10.1097/ PRS.0b013e3181904d5f.

32. Ossyssek B, Anders S, Grifka J, Straub RH. Surgical synovectomy decreases density of sensory nerve fibers in synovial tissue of non-inflamed controls and rheumatoid arthritis patients. J Orthop Res 2011; 29(2):297-02. doi: 10.1002/jor.21233.

33. Kortekaas MC, Kwok W-Y, Reijnierse M, Kloppenburg M. Inflammatory ultrasound features show independent associations with progression of structural damage after over 2 years of follow-up in patients with hand osteoarthritis. Ann Rheum Dis 2014; 74(9):1720-24. doi: 10.1136/ annrheumdis-2013-205003.

34. Mancarella L, Magnani M, Addimanda O, Pignotti E, Galletti S, Meliconi R. Ultrasound-detected synovitis with power Doppler signal is associated with severe radiographic damage and reduced cartilage thickness in hand osteoarthritis. Osteoarthritis Cartilage 2010; 18(10):1263-68. doi: 10.1016/j.joca.2010.06.006.

35. Keen HI, Wakefield RJ, Grainger AJ, Hensor EMA, Emery P, Conaghan PG. An ultrasonographic study of osteoarthritis of the hand: synovitis and its relationship to struc- tural pathology and symptoms. Arthritis Rheum 2008; 59(12):1756-63. doi: 10.1002/art.24312.

36. Veale D, Farrell M, Fitzgerald O. Mechanism of joint sparing in a patient with unilateral psoriatic arthritis and a longstanding hemiplegia. Br J Rheumatol 1993; 32(5):413-16. doi:10.1093/rheumatology/32.5.413.

37. Coste F, Forestier M. Hemiplegie et nodosities d'Heberden contralaterales. Bull Mem Soc Med Hop Paris $1935 ;$ 51:772-76.

38. Jacqueline F. A case of evolutive polyarthritis with localization contralateral to a hemiplegia. Rev Rheum Mal Osteoartic 1953; 20(4):323-24.

39. Thomson M, Bywaters EG. Unilateral rheumatoid arthritis following hemiplegia. Ann Rheum Dis 1962; 21(4):37077. doi: 10.1136/ard.21.4.370.

40. Mulherin D, Bresnihan B, Fitzgerald O. Digital denervation associated with absence of nail and distal interphalangeal joint involvement in psoriatic arthritis. J Rheumatol 1995; 22(6):1211-12.

41. Kane D, Lockhart P, Balint PV, Mann C, Ferrell WR, McInnes IB. Protective effect of sensory denervation in inflammatory arthritis (evidence of regulatory neuroimmune pathways in the arthritic joint). Ann Rheum Dis 2005; 64(2):325-27. doi: 10.1136/ard.2004.022277.

42. Stangenberg L, Burzyn D, Binstadt BA, Weissleder R, Mahmood U, Benoist C, et al. Denervation protects limbs from inflammatory arthritis via an impact on the microvasculature. Proc Natl Acad Sci U S A 2014; 111(31):1141924. doi: 10.1073/pnas.1410854111. 